\title{
Determining Reasons Affecting the Late Treatment of Congenital Talipes Equinovarus: A Qualitative Study
}

\author{
Panji Sananta ${ }^{1}$, Tita Hariyanti ${ }^{2}$, Ledy Kumala Devi ${ }^{1}$, \\ I Gusti Ngurah Arga Aldrian Oktafandi ${ }^{1} \&$ Felix Cendikiawan ${ }^{1}$ \\ ${ }^{1}$ Orthopaedic and Traumatology Department, Faculty of Medicine, Universitas Brawijaya-Saiful Anwar General \\ Hospital, Malang, East Java, Indonesia \\ ${ }^{2}$ Public Health Department, Faculty of Medicine, Universitas Brawijaya -Saiful Anwar General Hospital, Malang, \\ East Java, Indonesia \\ Correspondence: Panji Sananta, Orthopaedic and Traumatology Department, Faculty of Medicine, Universitas \\ Brawijaya -Saiful Anwar General Hospital, Jl. Jaksa Agung Suprapto No.2, Klojen, Malang 65112, East Java, \\ Indonesia.
}

Received: June 2, 2021 Accepted: August 15, 2021 Online Published: September 13, 2021

doi:10.5539/ghs.v13n10p91 URL: https://doi.org/10.5539/gjhs.v13n10p91

\begin{abstract}
Background: Neglected congenital talipes equinovarus (CTEV) is a serious problem commonly found in developing countries. This deformity has fatal impacts, including disabilities and educational limitations. Moreover, cases of neglected CTEV are still frequent in Indonesia as one of the developing countries. Thus, this study aims to investigate the reasons behind the late treatment of CTEV.

Methods: This is a qualitative study conducted throughout September 2019. The subjects are six parents of patients with neglected CTEV who are currently being treated in our hospital. The study was conducted by performing an in-depth interview with the patient's parents to analyze why they delay checking their child to an orthopaedic surgeon. The results were then grouped into themes.

Results: The reasons for the delay were multifactorial. Four subjects had more than one reason why they delayed checking their child to an orthopaedic surgeon. The reason for the delay were socioeconomic factors (3 subjects), medical-related problems ( 3 subjects), intentionally delayed or refused to seek medical care (2 subjects), and misinformation from the previous physician (3 subjects).
\end{abstract}

Conclusions: The reasons for the late treatment of CTEV were socioeconomic factors, medical-related problems, intentional factors, and misinformation.

Keywords: neglected CTEV, reasons, factors, qualitative study, interview

\section{Introduction}

Congenital talipes equinovarus (CTEV), or what is commonly called clubfoot, is a congenital abnormality in the foot that consists of a combination of cavus, forefoot adduction, varus, and equinus (Ponseti International Association, 2015). It is the most common congenital musculoskeletal disorder (Dobbs \& Gurnett, 2009). The incidence of CTEV is one to four cases every 1,000 live births, and most often occur in first-born children and boys (O'Shea \& Sabatini, 2016; Smythe et al., 2017). Moreover, $80 \%$ or about 100,000 cases per year are found in low and middle-income countries (Drew et al., 2018; Smythe et al., 2017).

Neglected CTEV is a case of CTEV caused by delays in early detection of the deformity at birth or in early infancy and lack of adequate management during infancy and childhood (Dimeglio \& Canavese, 2013). It is caused by poverty, lack of awareness, lack of access to health services, cultural beliefs, and superstitions.(Penny, 2005) As a result, a patient with neglected CTEV will have a difficult life due to his leg disability. They have to walk on the back of their feet, leading to chronic pain, ulcers, and infection. In addition, they cannot wear regular shoes. They tend to be excluded from society and ultimately cannot go to school (Naddumba, 2010). Meanwhile, the management of neglected CTEV includes surgeries that are considered difficult to perform.

Indonesia has around 267 million people with a total birth rate of 2.4 children for each woman in 2017 (Badan Kependudukan dan Keluarga Berencana Nasional, 2019; The World Bank, 2020). Moreover, Indonesia is still 
classified as a developing country with a middle income (International Monetary Fund, 2018). Up until now, there are no studies that calculate the prevalence rate of CTEV in Indonesia. However, with its high birth rates and status as a developing country, there are still many cases of neglected CTEV discovered in Indonesia. Thus, this study aims to evaluate the reasons behind the late treatment of CTEV.

\section{Methods}

It is a qualitative study conducted using a phenomenological approach. A qualitative study was chosen because it allows us to have a better understanding of problems in a heterogeneous population and patient condition, and identify steps to improve the quality of health services. Moreover, it helps us understand a health phenomenon that was initially difficult to comprehend. The study was conducted throughout September 2019 at the Saiful Anwar General Hospital, Malang, East Java, Indonesia.

The subjects of this study were six parents of patients with neglected CTEV who are currently being treated in our hospital. The number of samples was determined by the consecutive sampling technique. The inclusion criteria were parents of patients aged more than two years old with neglected CTEV who are currently being treated in our hospital and agreed to be interviewed. Patients with other congenital abnormalities apart from CTEV were also included. The exclusion criteria were parents of patients aged less than two years old with CTEV and parents of patients who refused to be interviewed. Parents of patients aged less than two years old were not included in the study because CTEV of less than two years could still be managed conservatively and is not categorized as neglected CTEV.

The study was performed by conducting an in-depth interview with the patient's parents using semistructured interview guidelines and recording it using a mobile phone. Through the interviews, we analyzed the reasons for the parent's delay in checking their children with an orthopaedic surgeon. Before the interview, all subjects agreed to the interview process by signing a letter of consent. All interviews were conducted by the same researcher in a closed room around the orthopaedic clinic or inpatient room.

The results of the recorded interviews were then typed verbatim using Microsoft Word. The Microsoft Word document was subsequently coded and divided into themes and subthemes. The research team conducted peer debriefing to analyze and conclude themes. Data that are not relevant to the study were then omitted. All processes were carried out using Microsoft Word Professional Plus 2019.

\section{Results}

There are six subjects in this study. All of them are the parents of patients with neglected CTEV who are currently being treated in our hospital. All subjects' profile is presented in Table 1 below.

Table 1. Subjects' profile

\begin{tabular}{ll}
\hline No. Subject & Profile \\
\hline & The 1st subject is the mother of a three-year-old patient with CTEV who is currently on routine \\
treatment at our hospital. She is a merchant selling food and snacks at the local market, and her \\
husband is an online transportation driver. She and her husband were in denial about their \\
child's condition that made them delaying or refusing to seek medical care. Moreover, the \\
economic factor also played a significant role because they had not joined the Indonesian \\
National Health Insurance at that time. Cultural and religious beliefs from the family member \\
also affected them. These multifactorial reasons caused the subject to delay bringing their child \\
into medical care.
\end{tabular}


The 4th subject is a mother who works as a local entrepreneur. Since her child was seven months old, she has been routinely going to a paediatrician for her child's cerebral palsy. The paediatrician suggested that the parents focus on the cerebral palsy treatment first and continue the CTEV treatment when their child reaches 12 years old. Their family moved several times to $4^{\text {th }}$ Subject (S4) other cities for working reasons. Finally, when the child reached 12 years old, they look for a new paediatrician around their new neighbourhood (Blitar City). The new paediatrician then suggested them to seek for an orthopaedic surgeon's help for the CTEV condition. After bringing their child to an orthopaedic surgeon, they just found out that their child's condition is supposed to be treated early.

The 5th subject is a housewife with a three years old child. Her husband works as a freelancer. They stopped seeking care for their child's condition because their past medical appointment at another hospital traumatized them. At that time, their child's foot got touched by the orthopaedic plaster cutting saw. In addition, they had not sought any medical care because they had financial difficulty and had not joined the Indonesian National Health Insurance at that time.

The 6th subject is a mother who works as a butcher at a traditional market. She started seeking medical care for her child's CTEV since her child reached five years old. Her child had a

$6^{\text {th }}$ Subject (S6) congenital heart defect, and their previous paediatrician suggested that she focus on treating the congenital heart defect first. At five years old, after the congenital heart defect had become stable, the paediatrician referred them to the orthopaedic department.

This study found four themes that make all the subjects delayed to get an orthopaedic treatment immediately at our hospital, including socioeconomic factors, medical-related factors, intentionally delayed or refused to seek medical care, and misinformation from their previous physician. These themes will be elaborated as follow:

\subsection{Socioeconomic Factors}

The socioeconomic factor is all factors that are related to economic that can significantly affect the social hierarchy and how well people live, such as income, education, employment, community safety, and social supports. In this study, some subjects had problems like medical cost, nomadic lifestyle, heavy workload, tight schedules or deadlines, and low health literacy about CTEV. In the end, these problems affected their decision making to seek a health care provider.

Some subjects in this study reported that they had difficulty paying the treatment cost for their child's CTEV. Therefore, they decided to discontinue or delay their CTEV treatment program.

"Yeah, at that time, the medical cost was too high for us. It cost us around Rp 400.000 for a single appointment with the doctor. It was quite hard for us." (S5)

"Previously, I had not joined the Indonesian National Health Insurance. We paid our previous medical expenses out of our pocket. It was quite hard for us because my husband only works as an online transportation driver. I had to ask my husband first before we go to the hospital. I was sad to see him go every day to work but still need to pay for the medical expenses." (S1)

Another problem like a nomadic lifestyle, living in a remote place, and also limited numbers of healthcare providers in their new neighbourhood became another hurdle for the subjects.

"Since 2010, we moved from Surabaya to Blitar. It was too far to bring my child to the same doctor every month. It was also quite difficult to look for a physiotherapist at Blitar. In the end, we gave up on our children's condition." (S4)

Some subjects also had tight work schedules and deadlines that make them cannot go to their children's medical appointments.

"Yes, I have a small business at Blitar. I used to have very tight schedules and deadlines. It made me cannot go to my child's therapy continuously." (S4)

"I used to go to the local market to sell some snacks or food every day. I woke up early to prepare the food and went to the market as fast as I can. I would go home in the late afternoon every day. At home, I had to clean up and did some household chores. We previously did not have any time to go for a medical appointment." (S1)

Some subjects admitted that they did not have any information about their children's diagnosis and treatment plan. 
"I did not know what it is (while giving a hesitant smile). All I used to know was that my child's foot just bending or bowing or something like that." (S5)

One of the subjects stated that she stopped the treatment because she did not see any improvement from their children's condition. Moreover, her other family members told her that her child's condition was not too severe so that she can be relaxed.

"I did not see any improvement from the treatment, so I decided to stop the treatment. My other family members also convinced me that my child's condition was not too severe and could be treated at home." (S5)

Some subjects admitted that they do not even know that their children's condition will worsen and will be more difficult to treat as the child grows.

"I do not know. Maybe my child can still be treated (while giving a hesitant smile), and I hope she can get better soon." (S5)

"I never know about my child's condition. All I know, his feet were normal when he was born. However, his feet became stiffer than before as time goes by." (S4)

\subsection{Medical-Related Factors}

Medical-related problems that often occur are other congenital disorders and psychological problems. Subjects in this study reported some medical disorders that become their primary concern than the CTEV condition.

"My first child's birth weight was around $600 \mathrm{~g}$. He was born at six months gestational age by normal labor at a hospital in Surabaya. At one year old, he was diagnosed with cerebral palsy. Immediately after he was born, he got transferred into NICU until his body weight reached $2500 \mathrm{~g}$. It took three months for him to get transferred out from NICU." (S4)

"When he was born, I was told that he had very dry skin and had to be treated in an incubator for 18 days. After that, my baby was diagnosed with a congenital heart defect. My child then got referred to another hospital for his heart problem." (S6)

A subject stated that her child got traumatized with the previous treatment for her CTEV because her foot got touched by the electrical plaster cutting saw.

"I knew that she has bowing feet. When she was two months old, I brought her to an orthopaedic surgeon, and her feet got plastered several times. One day, the electric plaster cutting saw touched her foot, and since that moment, I never come again for treatment (with a disappointed countenance)." (S5)

\subsection{Intentionally Delayed or Refused to Seek Medical Care}

Intentionally delayed or refused to seek medical care was caused by several factors, such as the parents' psychological state and family's religious beliefs. These factors affected the decision-making process by the parents and resulted in the delay in seeking medical care. A subject from this study stated that she was more concerned with the growth and development of her child, who was born prematurely, than with her child's feet abnormality.

"I did not bring him immediately to an orthopaedic surgeon because he was still very small. Thus, I first took care of him at home until he was eight months old, and then I brought him to an orthopaedic surgeon." (S2)

Another subject also stated that she and her husband were shocked and shaken when they discovered that their child was born with CTEV.

"My husband and I were shocked when we saw the condition of our child. I prayed a lot and hoped that this condition is just temporary. I even tried to straighten the feet by myself at home." (S1)

Moreover, a subject confessed that her family's religious belief also affected her decision to postpone seeking her child's treatment.

"My family and in-laws worried about my child's condition. My in-laws believed that some black magic causes my child's condition and suggested me to go to an ustad (a title for a man well educated in Islam used in the Middle East, South Asia, and Southeast Asia). The ustad then spelt a prayer to a bottle of water, and I was asked to drink it. He told me that the water I drink would be transferred to my child through breast milk and healed my child's disorder." (S1)

\subsection{Misinformation from the Previous Physician}

One of the subjects stated that one of their reasons to delay seeking medical help was because their previous paediatrician said that the CTEV was not the primary concern for the subject. 
"Yes, I have asked the paediatrician several times, and the paediatrician said that the primary focus for my child at that time is the congenital heart defect, not the feet problem." (S6)

Another subject was suggested by her paediatrician and previous orthopaedic surgeon that her child's condition did not require surgery and only needed to be rehabilitated. The subject's lack of knowledge made the subject obey the doctors' suggestions without seeking a second opinion.

"After several rehabilitation sessions, the paediatrician told me to continue the rehabilitation until my child reaches seven years old and can walk normally. However, my child still could not walk, and the muscles around my child's feet became very tight." (S4)

"When my child was younger, I also went to an orthopaedic surgeon. I asked him whether my child's condition requires surgery. Nevertheless, he suggested me to stick for the rehabilitation program and performed some stretchings on my child's feet. As a result, I never came back to him and just brought my child to the rehabilitation, as he suggested." (S4)

Moreover, some contrasting advice from different sources regarding the treatment for the child's CTEV made the subject confuse and finally decided to delay the treatment.

"A doctor said that my child did not need surgery and only needed rehabilitation, while another doctor said otherwise. These made me confuse and finally decided to delay the treatment." (S4)

Furthermore, another subject reported that she did not get any suggestions from her paediatrician to seek medical service from an orthopaedic surgeon.

"I asked my paediatrician about my child's medical condition, but she just told me that my child's feet abnormality is the result of being born prematurely, and I need to be patient with it. Because of that, I thought that my child's condition is just temporary." (S3)

"After several appointments with my previous paediatrician, I got referred to another paediatrician who is specialized in children's growth \& development. She told me that my children did not have cerebral palsy, but a bulge on the back. I forget the name of the disease. When I asked her what I should do, she just referred my child to the rehabilitation to get some therapies." (S3)

\section{Discussion}

In Indonesia, with a high population and birth rate, neglected CTEV is still frequently found in the community. Socioeconomic reasons, such as costs, limited access to adequate health services, and lack of knowledge, are obstacles for people with CTEV to obtain early and adequate management in Indonesia. Often, factors that prevent patients with CTEV from getting adequate treatment are multifactorial. In this study, four of the six subjects had more than one reason why they delayed checking their child to an orthopaedic surgeon. Three out of six subjects reported that their reason was because of socioeconomic problems. Of the socioeconomic problems, two subjects reported financial problems, two subjects stated that they had been too busy with their job, two subjects claimed to have insufficient knowledge of their child's condition, and one subject had limited access to adequate health services. Several studies supported these results. Studies by McElroy et al. (2007) and Kingau et al. (2015) found that poverty, long distances from residence to adequate health services, and parents' busywork were the reasons that caused neglected CTEV in their children. Avilucea et al. (2009), Gadhok et al. (2012), and Palma et al. (2013) also evaluated that the lack of parental knowledge about CTEV results in delays in managing their child's CTEV. A study in four countries, including Indonesia, also agreed that low economic levels, long distances to health facilities, and busy parents were the main reasons for neglected CTEV (van Wijck et al., 2015).

Goksan et al. (2015) and Avilucea et al. (2009) concluded that medical-related reasons also hampered adequate management of CTEV cases. They observed that lack of treatment adherence was a source of problems that prevented CTEV patients from obtaining complete management. Avilucea et al. (2009) even discovered that parents of patients often discontinued the wear of cast or shoes used to treat their child's CTEV prematurely. It is slightly different from the results found in this study. This study also reported medical-related reasons from three subjects, but these medical problems focused more on other illnesses suffered by the subjects' children and subjects' psychological trauma to the past management of their child's CTEV. This difference may be explained by the subject criteria used in the studies. Most of the other studies used the parents of patients with CTEV and without other concomitant diseases as their subjects. Meanwhile, this study did not exclude diseases other than $\mathrm{CTEV}$ as the criteria for subjects.

Moreover, this study discovered that two subjects intentionally refused or deferred treatment due to subjects' psychological factors and belief in alternative medicine. This result is consistent with the results reported by Burfat et al. (2013), Kingau et al. (2015), and Gadhok et al. (Gadhok et al., 2012) who observed that the factor of belief in 
traditional and religious cures is one of the problems faced in developing countries in providing adequate medical management for cases of CTEV. In addition, van Wijck et al. (2015), who conducted a study in Indonesia, also perceived that there were still many people who thought that CTEV was a supernatural event that could not be treated medically. A study by Burfat et al. (2013) in Pakistan reported that Pakistanis still believe that CTEV is a phenomenon associated with lunar and solar eclipses.

Furthermore, misinformation to the parents is also the reason for the delay in treatment for CTEV. This study discovered three out of six subjects who received inaccurate information or were not given any information at all from their previous doctors. Gadhok et al. (2012), Rasheed et al. (Rasheed \& aseem Rasheed Itaat Hussain Zaidi, 2017), and Burfat et al. (2013) found similar findings in their studies. Rasheed et al. (Rasheed \& aseem Rasheed Itaat Hussain Zaidi, 2017) perceived that $77.3 \%$ of their subjects admitted that they did not receive any information about their child's CTEV condition from the medical personnel. It is similar to the experience of the third subject in this study. The subject admitted that she did not get any information regarding her child's condition from the paediatrician. Meanwhile, the sixth and fourth subjects received inaccurate information regarding their child's CTEV. They were told that their child's CTEV does not need to be treated quickly and can wait until they get older. Gadhok et al. (2012) concluded that besides the level of knowledge of the patient's parents, the level of knowledge of doctors who treat patients with CTEV is also a factor that plays a vital role in managing CTEV. The combination of a patient's parents' lack of knowledge and inaccurate information about CTEV from doctors can result in neglected CTEV.

This study was conducted to know the reasons for the late treatment of CTEV. By knowing these reasons, a more focused approach can be made to prevent neglected CTEV. Approaches, such as screening to areas remote from health care centres, regular visits to CTEV patients' houses, counselling between health professionals and the patient's parents, establishing harmony and solidarity within the family, and providing quality care have been shown to reduce CTEV neglected incidence rate (McElroy et al., 2007). Furthermore, the Ponseti Virtual Forum, which is an educational forum about the early management of CTEV, has also been proven to increase public knowledge about CTEV (Wu et al., 2012).

The results of this study can determine what factors prevent parents of patients with CTEV from seeking treatment. However, this study still has limitations or weaknesses such as the number of subjects and the type of study. Further studies with a larger number of subjects will yield more varied perspectives on why parents of patients are late checking their child's CTEV. Moreover, further quantitative studies would be useful to statistically analyze the relationship between subjects' reasons and the various factors associated with neglected CTEV. Nonetheless, the results of this study suggest that a focused and comprehensive approach is needed to reduce the incidence of neglected CTEV.

\section{Conclusions}

This study found that the reasons that caused parents to delay checking their child's CTEV with an orthopaedic surgeon were socioeconomic factors, medical-related problems, intentional factors, and misinformation. Comprehensive and focused approaches to these factors can help reduce the incidence of neglected CTEV.

\section{Ethics Approval and Consent to Participate}

Ethical approval for this study was granted by the Ethical Committee of Medical Research Faculty of Medicine Universitas Brawijaya. All subjects agreed to the interview process by signing a letter of consent. The reference number is not available because this is a qualitative research, all participant identity has been treated anonymously, and there is no new/different intervention for the CTEV patient.

\section{Consent for Publication}

All subjects agreed that the data collected will be used for publication by signing a letter of consent.

\section{Acknowledgements}

Not applicable.

\section{Competing Interests Statement}

The authors declare that there are no competing or potential conflicts of interest.

\section{References}

Avilucea, F. R., Szalay, E. A., Bosch, P. P., Sweet, K. R., \& Schwend, R. M. (2009). Effect of Cultural Factors on Outcome of Ponseti Treatment of Clubfeet in Rural America. The Journal of Bone and Joint Surgery-American Volume, 91(3), 530-540. https://doi.org/10.2106/JBJS.H.00580

Badan Kependudukan dan Keluarga Berencana Nasional. (2019). Info Demografi. 
Burfat, A., Mohammed, S., Siddiqi, O., Samad, L., Khan, M. A., \& Chinoy, M. A. (2013). Understanding the knowledge and perceptions about clubfoot in Karachi, Pakistan: a qualitative exploration. The Iowa Orthopaedic Journal, 33, 149-152.

Dimeglio, A., \& Canavese, F. (2013). Management of resistant, relapsed, and neglected clubfoot. Current Orthopaedic Practice, 24(1), 34-42. https://doi.org/10.1097/BCO.0b013e31827ceb49

Dobbs, M. B., \& Gurnett, C. A. (2009). Update on Clubfoot: Etiology and Treatment. Clinical Orthopaedics and Related Research, 467(5), 1146-1153. https://doi.org/10.1007/s11999-009-0734-9

Drew, S., Gooberman-Hill, R., \& Lavy, C. (2018). What factors impact on the implementation of clubfoot treatment services in low and middle-income countries?: a narrative synthesis of existing qualitative studies. BMC Musculoskeletal Disorders, 19(1), 72. https://doi.org/10.1186/s12891-018-1984-z

Gadhok, K., Belthur, M. V, Aroojis, A. J., Cook, T., Oprescu, F., Ranade, A. S., \& Morcuende, J. A. (2012). Qualitative assessment of the challenges to the treatment of idiopathic clubfoot by the Ponseti method in urban India. The Iowa Orthopaedic Journal, 32, 135-140.

Göksan, S. B., Bilgili, F., Eren, İ., Bursalı, A., \& Koç, E. (2015). Factors affecting adherence with foot abduction orthosis following Ponseti method. Acta Orthopaedica et Traumatologica Turcica, 49(6), 620-626. https://doi.org/10.3944/aott.2015.14.0348

International Monetary Fund. (2018). World Economic Outlook.

Kingau, N. W., Rhoda, A., \& Mlenzana, N. (2015). Barriers experienced by service providers and caregivers in clubfoot management in Kenya. Tropical Doctor, 45(2), 84-90. https://doi.org/10.1177/0049475514564694

McElroy, T., Konde-Lule, J., Neema, S., Gitta, S., \& The Uganda Sustainable Clubfoot Car. (2007). Understanding the barriers to clubfoot treatment adherence in Uganda: A rapid ethnographic study. Disability and Rehabilitation, 29(11-12), 845-855. https://doi.org/10.1080/09638280701240102

Naddumba, E. (2010). Preventing neglected club feet in Uganda: A challenge to the health workers with limited resources. East African Orthopaedic Journal, 3(1). https://doi.org/10.4314/eaoj.v3i1.62560

O'Shea, R. M., \& Sabatini, C. S. (2016). What is new in idiopathic clubfoot? Current Reviews in Musculoskeletal Medicine, 9(4), 470-477. https://doi.org/10.1007/s12178-016-9375-2

Palma, M., Cook, T., Segura, J., Mayo, L., \& Morcuende, J. A. (2013). Barriers to the Ponseti method in Peru: a two-year follow-up. The Iowa Orthopaedic Journal, 33, 172-177.

Penny, J. N. (2005). The Neglected Clubfoot. Techniques in Orthopaedics, 20(2), 153-166. https://doi.org/10.1097/01.bto.0000162987.08300.5e

Ponseti International Association. (2015). Guideline Title Clinical Practice Guidelines for the Management of Clubfoot Deformity Using the Ponseti Method Bibliographic Source(s).

Rasheed, N., \& Naseem Rasheed Itaat Hussain Zaidi, G. H. (2017). Awareness Regarding Clubfoot in Parents. Journal of Pakistan Orthopaedic Association, 29(03 SE-), 90-94.

Smythe, T., Kuper, H., Macleod, D., Foster, A., \& Lavy, C. (2017). Birth prevalence of congenital talipes equinovarus in low- and middle-income countries: a systematic review and meta-analysis. Tropical Medicine \& International Health, 22(3), 269-285. https://doi.org/10.1111/tmi.12833

The World Bank. (2020). Indonesia Overview.

van Wijck, S. F. M., Oomen, A. M., \& van der Heide, H. J. L. (2015). Feasibility and barriers of treating clubfeet in four countries. International Orthopaedics, 39(12), 2415-2422. https://doi.org/10.1007/s00264-015-2783-x

Wu, V., Nguyen, M., Nhi, H. M., Thanh, D. Van, Oprescu, F., Cook, T., \& Morcuende, J. A. (2012). Evaluation of the progress and challenges facing the Ponseti method program in Vietnam. The Iowa Orthopaedic Journal, $32,125-134$.

\section{Copyrights}

Copyright for this article is retained by the author(s), with first publication rights granted to the journal.

This is an open-access article distributed under the terms and conditions of the Creative Commons Attribution license (http://creativecommons.org/licenses/by/4.0/). 